\title{
Temporal and spatial variation in heritability and genetic correlations among floral traits in Raphanus sativus, wild radish
}

\author{
HELEN J. YOUNG*, MAUREEN L. STANTON†, NORMAN C. ELLSTRAND \& \& JANET M. \\ CLEGG $\ddagger$ \\ Department of Biology, Barnard College, 3009 Broadway, New York, NY 10027-6598, $\dagger$ Section of Evolution and Ecology, \\ University of California, Davis, CA 95616-8755 and $\ddagger$ Department of Botany and Plant Sciences and Program in Genetics, \\ University of California, Riverside, CA 92521, U.S.A.
}

\begin{abstract}
We measured heritability and genetic correlations of three floral traits (corolla width, pollen production per flower and pollen size) in two generations of wild radish (Raphanus sativus) grown in three growth environments (two field sites and the greenhouse). Corolla width and pollen production showed significant heritabilities in both generations and under all growth environments, while pollen size variation appears to be under little genetic control. The estimates of heritability did not vary significantly among generations or among the growth environments. Genotype-environment interactions were not apparent for any trait. Apparently, similar selection pressures will result in similar phenotypic changes across generations and across sites. Only corolla width and pollen production were significantly genetically correlated; families with large corollas also had large pollen production. Therefore the direction and magnitude of evolutionary change of these two traits are dependent on the relative selection pressures on each.
\end{abstract}

Keywords: genetic correlations, genotype-environment interactions, heritability, Raphanus sativus, wild radish.

\section{Introduction}

If selection is to operate on intraspecific variation, several conditions must be met. Firstly, fitness must vary with phenotypic variation. For natural plant populations, there are many examples where phenotypic variation has been correlated with fitness. Patterns of allocation to vegetative structures often influence survivorship and growth rate (Jordan, 1991; Stratton, 1992a) and patterns of allocation to sexual structures can affect mating and reproductive success (reviewed in Stanton \& Galloway, 1990). Apparently phenotypic selection operates frequently in plant populations and at multiple stages in the life cycle.

Secondly, natural selection must be able to act to change the pattern of phenotypic variation in subsequent generations, i.e. phenotypic variation must have a genetic basis. The extent to which phenotypic selection on parents will influence the distribution of progeny genotypes is determined by the heritability

${ }^{*}$ Correspondence.
( $h^{2}$ : the proportion of total phenotypic variation that is explained by additive genetic variance, $V_{\mathrm{A}}$ ) of the trait in question. For a given selection intensity, traits with low heritability (low $V_{\mathrm{A}}$ ) will respond more slowly than traits with higher heritability (Falconer, 1989). Therefore, relative values of heritability of various traits are useful in predicting which traits will respond most rapidly to selection.

It has been widely thought that traits closely associated with fitness will have low heritability because stabilizing selection has acted on those traits over time, reducing their genetic variation (Stearns, 1980; Falconer, 1989). This belief has been generally supported both theoretically (Price \& Schluter, 1991) and empirically (Gustafsson, 1986; Mousseau \& Roff, 1987; Roff \& Mousseau, 1987). However, several studies have found heritabilities of traits closely correlated with fitness to be quite high (Giesel et al., 1982; Mitchell-Olds, 1986; Mousseau \& Roff, 1987). Although knowledge of the heritabilities of traits may be helpful in predicting how rapidly the phenotype of the population has the potential to change over time, 
their relative magnitudes may reveal little about how closely the traits are related to fitness. Houle (1992) has found that fitness traits (survivorship, longevity) have greater additive genetic coefficients of variation $\left(C V_{\mathrm{A}}\right)$ than morphological characters, possibly because of the larger number of genetic and environmental factors by which they are affected or the lack of stabilizing selection on these traits. The concept of measuring the standardized variation of $V_{\mathrm{A}}$ ('evolvability'; Houle, 1992) for different traits is useful because of the intuitive relationship between the amount of genetic variation of a trait and the rate of response to selection: if a population has little genetic variation for a trait, the response to selection will be very slow, even if the trait exhibits strong heritability.

Owing to the difficulty in determining parentage under natural conditions, controlled breeding in controlled environments is frequently used to measure heritability. This is usually done with the assumption that controlled conditions, such as greenhouses or growth chambers, have lower environmental variation $\left(V_{E}\right)$ than field conditions (but see Potvin et al., 1990). While minimizing $V_{\mathrm{E}}$ is convenient for estimating $V_{\mathrm{A}}$, the relevance of controlled heritability measures in the laboratory or greenhouse to natural populations is not entirely clear. Because genes (pollen or seeds) often disperse from parental microhabitats and environmental heterogeneity is ubiquitous, predicting the direction and magnitude of genetic changes across generations requires information on the consistency and strength of heritability across different natural environments. In addition, if the ranks of phenotypes of several genotypes change in different environments ( $\mathrm{G} \times \mathrm{E}$ interaction), natural selection will favour different genotypes in each environment (Fig. 1 in Mazer \& Schick, 1991a). The presence of $\mathrm{G} \times \mathrm{E}$ will retard evolutionary change. It is important to design experiments that test genotypes in natural environments to reveal the importance of $\mathrm{G} \times \mathrm{E}$ in phenotypic evolution. If no $\mathrm{G} \times \mathrm{E}$ exists and selection pressures are similar, the same genotype will be favoured in all environments and consistent directional change in phenotype will result.

In this paper, we describe genetic studies on wild radish, Raphanus sativus, focusing on traits known to have observable effects on fitness components. Because the evolutionary ecology of this wild species has been studied extensively in California (Ellstrand, 1984; Marshall \& Ellstrand, 1986; Stanton, 1987; Stanton \& Preston, 1986, 1988; Young \& Stanton, 1990; Stanton et al., 1991), its reproductive ecology is unusually well understood. A high degree of phenotypic variation has been documented for petal colour (Panetsos \& Baker, 1964; Stanton, 1987), ovule number (Stanton \& Preston, 1988), and petal size, pollen production per flower, and pollen size (Stanton \& Preston, 1986, 1988; Young \& Stanton, 1990).

Genetic analyses of phenotypic variation in wild radish are especially valuable because there are known ecological consequences of floral variation. Petal size is a strong predictor of visitation by honey-bees and large flowers typically export pollen faster than small flowers (Young \& Stanton, 1990). In contrast, large flowers do not have greater female reproductive allocation or success than small flowers (Stanton \& Preston, 1988; Young \& Stanton, 1990). Pollen production per flower is known to affect both pollinator visitation and components of male reproduction. Pollen production is a strong predictor of visitation by small native bees (other than Agapostemma; Stanton et al., 1991) and although honey-bees appear insensitive to small differences in pollen production, they avoid flowers from which all pollen has been removed (Young \& Stanton, 1990). Total pollen export increases with pollen production; more pollen is removed per visit and, in some cases, a higher proportion of pollen is exported from flowers with large pollen production (Young \& Stanton, 1990). In small experimental populations, increased pollen production has a positive effect on seed paternity (Stanton et al., 1991). Pollen grain size might be expected to influence pollen performance (Kumar \& Sarkar, 1980; Cruzan, 1990) and/or flower attractiveness. Most pollinators show no direct response to pollen size but honey-bees significantly overvisited flowers with large pollen grains (Stanton et al., 1991). Preliminary analyses show no evidence of a direct effect of pollen size on postpollination fertilization success in $R$. sativus (Stanton et al., 1991).

We used a positive assortative mating scheme to select for specific phenotypes relating to flower size, pollen production and pollen size. To examine possible limitations of heritability analyses from common controlled environments, parents and offspring were grown in the field, greenhouse or both. We used midparent-offspring regression to estimate heritability expressed across these environments and to determine the genetic correspondence between phenotypic characters. Positive assortative mating provides an unbiased estimate of $h^{2}$ when regressions are used and this mating design results in low standard errors of the $h^{2}$ estimate (Falconer, 1989). In addition, assortative mating has no effect on the slope of the midparentoffspring regression $\left(h^{2}\right)$ either within or across environments (Riska et al., 1989; but see Gimelfarb, 1985).

In this paper, we address the following issues. (i) is genetic control for these floral traits expressed consistently under different growth conditions? If heritability 
estimates are consistent across environments, then we can predict future phenotypes without regard to the particular environment each generation is experiencing. (ii) Does genotype $\times$ environment interaction $(\mathrm{G} \times \mathrm{E})$ have an effect on changing progeny phenotypic distributions? If $\mathrm{G} \times \mathrm{E}$ exists, then knowledge of the relative abundance of the different environments and the dispersal patterns of offspring into those environments is needed to predict phenotypes of future generations. (iii) Are the floral traits genetically correlated? How do environmental conditions affect these correlations? The degree to which natural selection can act independently on specific traits is limited by genetic correlations with other traits under selection (Antonovics, 1976; Lande \& Arnold, 1983). If genetic correlations vary with environment, then phenotypes of future generations can be predicted only with knowledge of the relative abundance of environments.

\section{Materials and methods}

\section{First generation: parents in the field, offspring in the greenhouse}

In March 1986, a large number of wild radish individuals was assayed in the field (two field sites near Davis, CA: Airport Site and Campus Site; see Stanton \& Preston, 1988 for details) for three floral traits: corolla width (the distance from one petal tip to the tip of the opposite petal), pollen production per flower and pollen volume (the latter two traits were measured using an electronic particle counter: see Young \& Stanton, 1990 for a description of the techniques). We performed hand-pollinations and carried out a breeding programme of positive assortative mating for each of the three floral traits (for three sets of positively assortatively mated traits). In total, we had 36 mated pairs of plants (14 pairs specifically for flower size, 11 pairs for pollen number and 11 pairs for pollen size). Inflorescences were bagged with netting before flowers opened and freshly opened flowers were pollinated with pollen from the appropriate pollen donor. Thirtyfour plants produced sufficient fruit and/or seed for progeny analysis. Mature fruits were collected in May 1986 and the seeds of these fruits $\left(F_{1}\right)$ were planted individually in $10 \mathrm{~cm}$ pots in the UC-Davis greenhouse in September 1986 (10-15 seeds per family). Positions of the pots within the greenhouse were randomly assigned and positions were randomly rotated weekly. Plants were fertilized with 10 per cent Hoagland's solution weekly. In total, 362 seeds germinated. We performed electrophoresis to confirm the parentage of each seedling. Data from 29 per cent of the seedlings were deleted from analyses because of possible pollen contamination (they were sired by plants other than the expected plants). As each progeny came into flower, corolla width was measured for the sixth, seventh and eighth flower produced (the first flowers produced on radish plants have unusually large petals and high pollen counts, M. Stanton, personal observation). Nearly mature buds of flowers 9-11 were collected for determination of pollen production and pollen size.

Heritabilities of these floral traits were calculated (see below). Heritabilities measured when parents are grown in nature and offspring grown in the laboratory represent lower bounds on $h^{2}$ in natural environments (Riska et al., 1989).

\section{Second generation: parents in the greenhouse, offspring in the greenhouse and two field sites}

A subset of the $F_{1}$ individuals was chosen for a second generation of positive assortative mating on the basis of petal size ( $n=13$ pairs) and pollen production $(n=7$ pairs). Unrelated individuals were chosen as parents and hand-pollinations were performed in the greenhouse in December 1986 and January 1987. Nineteen of the 20 pollen recipients produced fruits. Mature fruits from these pollinations were collected approximately 1 month after pollination and seeds $\left(F_{2}\right)$ were planted in $2.5 \mathrm{~cm}$ pots in October. In November 1987, seedlings of each full-sib family were divided into three groups for transplanting: 10 were planted individually in $10 \mathrm{~cm}$ pots in the greenhouse and 10 were transplanted into each of two sites at the Campus site, 190 seedlings per site. The field sites were $30 \mathrm{~m}$ apart in a field densely populated with wild $R$. sativus. The seedlings were planted in a randomized block design with genotype replicated in each of five rows, rows and columns being $50 \mathrm{~cm}$ apart. $\mathrm{F}_{2}$ seedlings planted in the greenhouse were randomly placed on benches and the pots were rotated randomly every two weeks. Flowering began in mid-December 1987 in the greenhouse and in early February 1988 in the field. As each $F_{2}$ individual flowered, corolla widths of three flowers were measured and flower buds were collected for determination of pollen production and pollen size.

\section{Statistical analyses}

Regressions were performed using the mean offspring values and mid-parent values for each family (PROC REG: SAS, 1988) for each of three traits (pollen number, modal pollen size and corolla diameter). Narrow sense heritability (additive genetic variance) is the slope of this regression (Falconer, 1989). The standard error of $h^{2}$ is the standard error of the slope given in PROC REG. 
For each trait, heritabilities were calculated in two ways: (1) for the specifically selected lines only $(n=11-14$ families in the first generation, $n=5-7$ families for the second generation), and (2) for the entire set of parents and progeny for each generation $(n=34$ families for the first generation, $n=19$ for the second generation). For example, midparent-offspring values of corolla width from the first generation of breeding are plotted in Fig. 1; the selected lines are represented with open circles. The regression between mid-parent and offspring values of the selected line has a slope of $0.47(\mathrm{SE}=0.061)$ while the entire data set has a slope of $0.41(\mathrm{SE}=0.076)$. The $h^{2}$ estimates are not significantly different from the two data sets for all traits and therefore the estimates calculated from the entire data set are presented for each generation in the remainder of the paper.

Genetic correlations, $r_{\mathrm{G}}$, among the three traits (pollen number, pollen size and corolla width) were calculated using the following equation (Boag, 1983; Soltis, 1986):

$r_{\mathrm{G}}=\frac{\operatorname{cov}_{\mathrm{xy}}}{\sqrt{\operatorname{cov}_{\mathrm{xx}} \operatorname{cov} v_{\mathrm{yy}}}}$,

where $c o v_{\mathrm{xy}}=b_{\mathrm{yx}} \sigma_{\mathrm{Px}}^{2}, b_{\mathrm{yx}}=$ slope of the mid-parent (trait $y$ ), offspring (trait $x$ ) regression, $\sigma_{\mathrm{Px}}^{2}=$ variance in mid-parent trait $x, c o v_{\mathrm{xx}}=b_{\mathrm{xx}} \sigma_{\mathrm{Px}}^{2}$ and $c o v_{\mathrm{yy}}=b_{\mathrm{yy}} \sigma_{\mathrm{Py}}^{2}$.

It is possible to calculate two genetic correlations for each pair of traits, one with the numerator $\operatorname{cov}_{\mathrm{xy}}$ and the other with the numerator $\operatorname{cov}_{\mathrm{yx}}$. We calculated $r_{\mathrm{G}}$ as the mean of these formulae (Boag, 1983; Coyne \& Beecham, 1987; Leamy, 1988). The standard error of

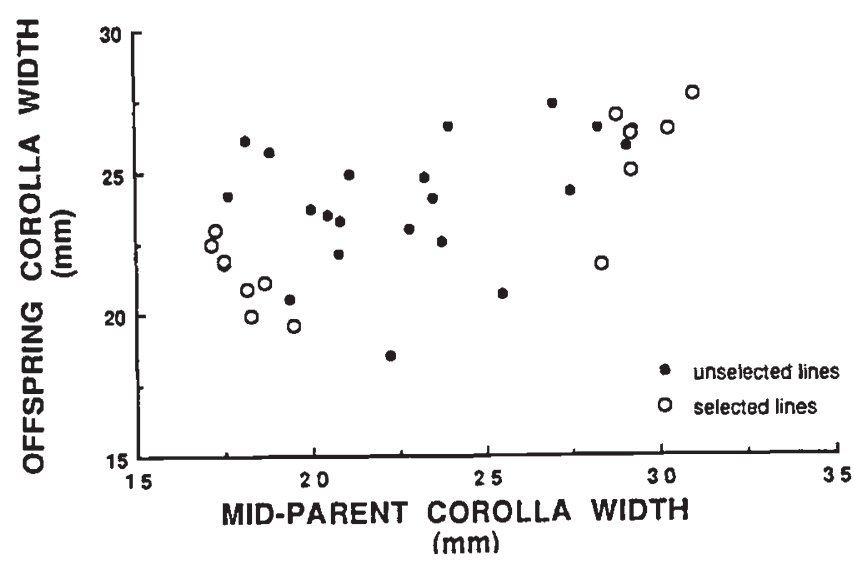

Fig. 1 Plot of mid-parent, offspring values for corolla width from the first generation of breeding. Fourteen pairs of parents were positively assortatively mated; these are represented by open circles. The remaining parental pairs were mated on the basis of pollen number or pollen size.
$r_{\mathrm{G}}$ was calculated using (Soltis, 1986; Falconer, 1989):

$$
\mathrm{SE}=\frac{1-r_{\mathrm{G}}^{2}}{\sqrt{2}} \sqrt{\frac{\mathrm{SE}\left(h_{\mathrm{x}}^{2}\right) \mathrm{SE}\left(h_{\mathrm{y}}^{2}\right)}{h_{\mathrm{x}}^{2} h_{\mathrm{y}}^{2}}} \text {. }
$$

The standard error of the genetic correlation was calculated using both cross-covariances in the numerator of $r_{\mathrm{G}}\left(\operatorname{cov}_{\mathrm{xy}}\right.$ and $\left.c o v_{\mathrm{yx}}\right)$ and the average of both standard errors is reported. Both $h^{2}$ and $r_{\mathrm{G}}$ were calculated separately for the $F_{1}$ grown in the greenhouse and the $F_{2}$ grown in the three environments (two field sites and the greenhouse). Analysis of variance was used to detect genotype-environment interactions $(G \times E)$ for the $F_{2}$ progeny grown in three environments. A significant interaction term for family-by-growth environment $(G \times E)$ suggests that phenotypic variance among families is strongly influenced by growing conditions.

To measure the evolvability of each trait, the coefficient of variation of additive genetic variation was calculated as $C V_{\mathrm{A}}=100\left(\sqrt{V_{\mathrm{A}}} / / \bar{x}\right.$ of the trait before selection)) (Houle, 1992).

\section{Results}

The phenotypes for the three floral traits of the parents and offspring of the two generations are presented in Table 1. A within-generation comparison of phenotypes was made for the $F_{2}$ grown in three different environments using ANOVA (PROC GLM, SAS, 1988): all floral traits varied significantly among environments in which the offspring were raised. For example, corolla size was significantly larger for plants growing in the greenhouse than for their full-sibs grown in the field. Pollen production per flower varied among all three sites and was significantly lower for the offspring grown in the greenhouse. This implies that environmental variation plays a large role in determining floral phenotypes.

The site-by-family interaction $(\mathrm{G} \times \mathrm{E})$ was not significant for any of the traits (site $\times$ family line in Table 2 ), meaning that although there was significant variation among full-sib families for each trait, the overall rank of each family in each environment was relatively unchanged across environments. The mean floral phenotype for each full-sib family in each environment is presented in Fig. 2. Although some of the reaction norms cross, the relative position of each family did not change significantly among sites. For example, the family with the largest pollen production in field site 1 also had the largest production in field site 2 and the second largest production in the greenhouse.

Both pollen production and corolla size exhibited heritabilities significantly greater than zero in both generations and in all three growth environments 
(Table 3). To detect differences in heritability among the three growth environments of the progeny in the $F_{2}$, we used PROC GLM (SAS, 1988) testing for differences among sites in the slope of the mid-parent-offspring regression. Heritabilities did not differ significantly among sites (for the site $\times$ trait interaction, $P=0.25$, 0.21 , and 0.72 for pollen production, pollen size and corolla size, respectively). Therefore, although the

Table 1 Phenotypic values of parents and offspring for two generations of breeding

\begin{tabular}{|c|c|c|c|c|c|c|}
\hline \multirow{2}{*}{$\begin{array}{l}\text { Generation: } \\
\text { Grown in: }\end{array}$} & \multirow{2}{*}{$\begin{array}{l}\text { Parents } \\
\text { Field }\end{array}$} & \multirow{2}{*}{$\begin{array}{c}F_{1} \\
\mathrm{GH}\end{array}$} & \multirow{2}{*}{$\begin{array}{c}\mathrm{F}_{1} \text { used as } \\
\text { parents } \\
\mathrm{GH}\end{array}$} & \multicolumn{3}{|c|}{$F_{2}$ grown in: } \\
\hline & & & & Field 1 & Field 2 & GH \\
\hline $\begin{array}{l}\text { Pollen number } \\
\text { per flower }\end{array}$ & $\begin{array}{c}154,776 \\
(30,773.4)\end{array}$ & $\begin{array}{c}135,990 \\
(30,190.2)\end{array}$ & $\begin{array}{c}133,507 \\
(22,720.9)\end{array}$ & $\begin{array}{c}139,988^{\mathrm{B}} \\
(37,869.7)\end{array}$ & $\begin{array}{r}153,895^{A} \\
(35,170.0)\end{array}$ & $\begin{array}{c}125,362^{C} \\
(23,658.7)\end{array}$ \\
\hline $\begin{array}{l}\text { Pollen volume } \\
\qquad\left(\mu \mathrm{m}^{3}\right)\end{array}$ & $\begin{array}{c}4452 \\
(402.1)\end{array}$ & $\begin{array}{c}4474 \\
(400.4)\end{array}$ & $\begin{array}{c}4546 \\
(265.9)\end{array}$ & $\begin{array}{c}4588^{\mathrm{B}} \\
(741.7)\end{array}$ & $\begin{array}{l}4751^{\mathrm{AB}} \\
(483.0)\end{array}$ & $\begin{array}{l}4844^{\mathrm{A}} \\
(620.8)\end{array}$ \\
\hline $\begin{array}{l}\text { Corolla width } \\
(\mathrm{mm})\end{array}$ & $\begin{array}{c}22.84 \\
(4.56) \\
34 \text { pairs }\end{array}$ & $\begin{array}{c}23.51 \\
(3.25) \\
257\end{array}$ & $\begin{array}{l}23.93 \\
(3.55) \\
\end{array}$ & $\begin{array}{c}20.35^{\mathrm{B}} \\
(3.44)\end{array}$ & $\begin{array}{l}21.61^{\mathrm{B}} \\
(3.43)\end{array}$ & $\begin{array}{l}23.75^{\mathrm{A}} \\
(2.88)\end{array}$ \\
\hline$N$ & 34 pairs & 257 & 20 pairs & 69 & 75 & 77 \\
\hline
\end{tabular}

Mean (and SD) are presented.

ANOVA results testing for among-site differences of $F_{2}$ grown in three environments: pollen number, $F_{2,213}=14.5, P<0.001$; pollen size, $F_{2,214}=3.1, P=0.047$; corolla width, $F_{2,222}=26.5, P<0.001$.

Mean values for $\mathrm{F}_{2}$ followed by different letters are significantly different at $P<0.05$ (Tukey's test).

Table 2 Variance components of three floral traits among $\mathrm{F}_{2}$ progeny grown in three different environments

\begin{tabular}{lccc}
\hline & Pollen number & Pollen volume & Corolla width \\
\hline Site $\left(V_{\mathrm{E}}\right)($ d.f. $=2)$ & & & \\
$\mathrm{MS} \dagger$ & 1.7098 & 882,599 & 163.95 \\
$F$ & 20.31 & 2.55 & 27.33 \\
$P$ & $<0.001$ & 0.08 & $<0.001$ \\
Variance component $\neq$ & 0.0276 & 9167 & 2.524 \\
$\%$ of total variance & 20.3 & 2.3 & 18.5 \\
Family $\left(V_{\mathrm{A}}\right)$ (d.f.=18) & & & \\
MS & 0.3305 & 770,782 & 59.47 \\
$F$ & 3.93 & 2.22 & 9.92 \\
$P$ & $<0.001$ & 0.004 & $<0.001$ \\
Variance component & 0.0239 & 41,725 & 4.720 \\
$\%$ of total variance & 17.6 & 10.6 & 34.6 \\
Site $\times$ family $($ d.f. $=34)$ & & & \\
MS & 0.0842 & 333,548 & 7.50 \\
$F$ & 1.00 & 0.96 & 1.25 \\
$P$ & 0.48 & 0.53 & 0.18 \\
Variance component & -0.000002 & -3460 & 0.3793 \\
$\%$ of total variance & -0.002 & -0.88 & 2.8 \\
Error (d.f.=161) & & & \\
MS & 0.0841 & 346,696 & 5.99 \\
Variance component & 0.0841 & 346,696 & 5.99 \\
$\%$ of total variance & 62.0 & 86.2 & 44.0 \\
\hline
\end{tabular}

$\dagger$ Type III mean squares are presented from PRoc GLM (SAS Institute, 1988) with site and family as random effects.

$\ddagger$ Variance components were calculated by equating the observed and expected mean squares (from PROC GLM) and solving for the variance components, using site and family as random effects. Negative variance components are due to sampling error. 

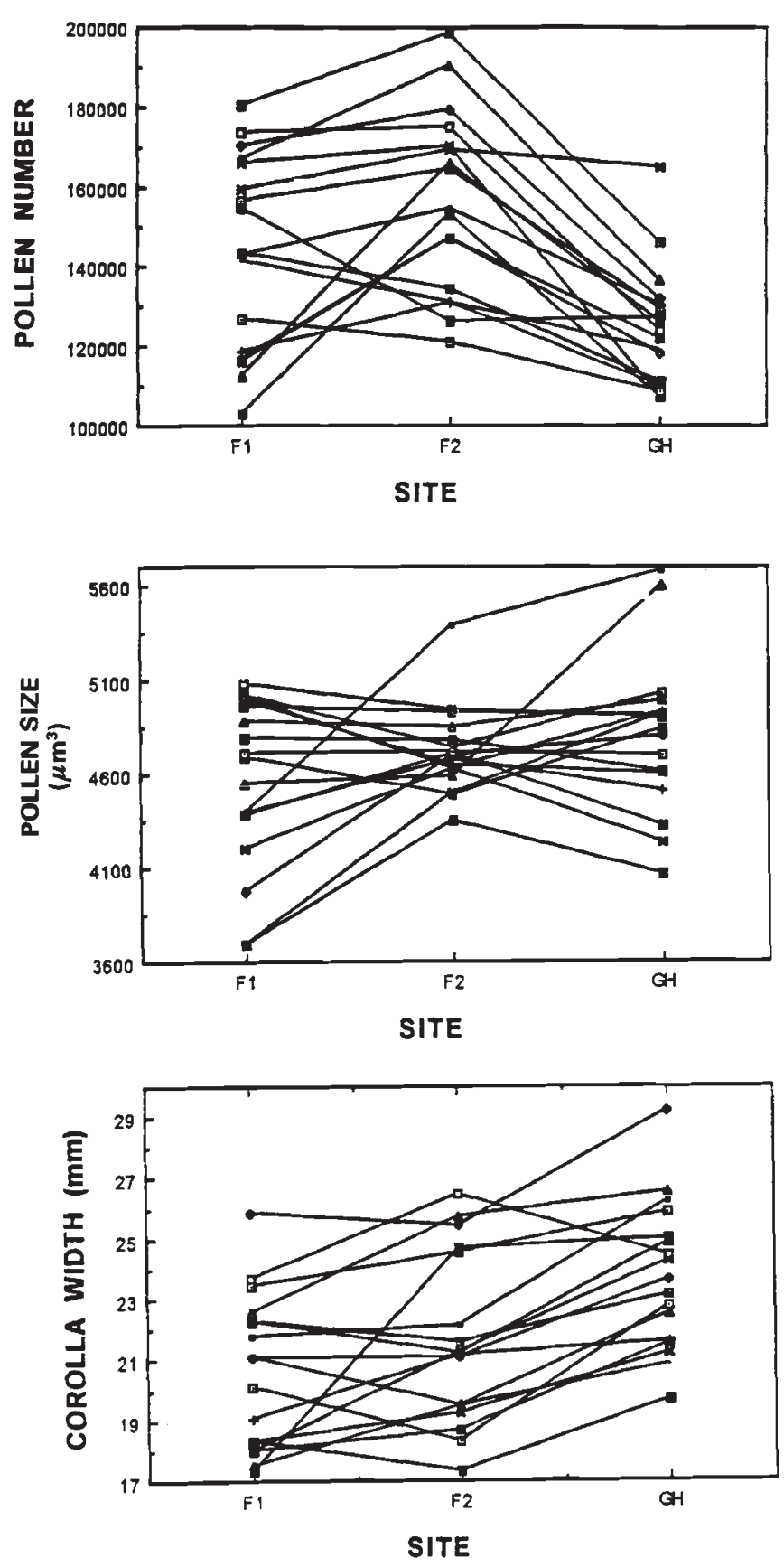

Fig. 2 Norms of reactions of floral traits of 19 full-sib families in three environments $(F 1=$ field site $1 ; F 2=$ field site 2 ; $\mathrm{GH}=$ greenhouse). $\mathrm{G} \times \mathrm{E}$ was not significant for any of these traits (see Table 3).

growth environment of the progeny significantly influenced their floral phenotypes, the additive genetic variance did not vary significantly from site to site.

Heritability estimates from the greenhouse did not differ from those in the field, although we expected the greenhouse environment to be more environmentally stable and uniform across generations than the field sites. Reduced environmental variance in the greenhouse would increase the possibility of measuring significant trait heritability. Instead we find that heritability estimates are as great, and sometimes greater (for pollen production, although not significantly), for progeny grown in the field compared with those in the greenhouse. In addition, heritability estimates for the three traits did not differ between the two generations (trait $\times$ generation in GLM (SAS, 1988), $P=0.81,0.61$ and 0.26 for pollen production, pollen size and corolla size, respectively).

Only pollen number and corolla width were significantly genetically correlated (Table 4). This correlation was high and positive in both generations and in all growth environments of the $\mathrm{F}_{2}$. Therefore, selection for increased corolla size should lead to concurrent increases in pollen production and vice versa.

\section{Discussion}

Mitchell-Olds and Rutledge (1986) emphasize the need for measurement of heritability and genetic correlations under natural conditions. To predict the potential responses to selection, one needs measures of the constancy (both spatial and temporal) of quantitative genetic parameters for the traits of interest. Knowledge of the magnitude of heritability and $\mathrm{G} \times \mathrm{E}$ of a trait allows predictions to be made about the effect of environmental changes, long-distance gene flow and selection on phenotypic changes in the population. For instance, if heritability estimates are not consistent across environments (Fig. 3c,d; Mitchell-Olds, 1986), then the impact of selection will vary with the environment in which the plant is growing. In populations where the trait is under strong genetic control (high heritability), selection will result in predicted changes in the phenotype; but in populations where heritability for that trait is low (and $V_{\mathrm{E}}$ is high), no predictions can be made about the effect of selection on the phenotypes of future generations. In addition, if $\mathrm{G} \times \mathrm{E}$ exists, making predictions about phenotypes of future generations requires knowledge of the relative abundances of genotypes in all environments and the relative abundances of all environments (Stratton, 1992b). In the absence of $G \times E$, the genotype favoured by selection will remain unchanged across environments.

In this study of wild radish, heritabilities of corolla width and pollen production are consistent across the three environments measured and there is no evidence of $\mathrm{G} \times \mathrm{E}$ for these traits. Therefore, selection acting on these traits will result in consistent changes in the phenotypic values of the traits among the environments if selection is of the same magnitude and direction in 
Table 3 Heritabilities from mid-parent, mean offspring regressions

\begin{tabular}{|c|c|c|c|c|c|}
\hline & \multirow[t]{2}{*}{ Parent $\rightarrow F_{1}$} & \multicolumn{3}{|c|}{$\mathrm{F}_{1} \rightarrow \mathrm{F}_{2}$} & \multirow[t]{2}{*}{ Total $F_{1} \rightarrow F_{2}$} \\
\hline & & Field 1 & Field 2 & $\mathrm{GH}$ & \\
\hline $\begin{array}{c}\text { Pollen number } \\
\text { per flower } \\
C V_{\mathrm{A}}(\%)\end{array}$ & $\begin{array}{c}\mathbf{0 . 4 3} \pm 0.122 \\
P=0.0014 \\
13.0\end{array}$ & $\begin{array}{l}\mathbf{0 . 7 5} \pm 0.209 \\
P=0.002\end{array}$ & $\begin{array}{c}\mathbf{0 . 6 4} \pm 0.188 \\
P=0.003\end{array}$ & $\begin{array}{c}\mathbf{0 . 3 3} \pm 0.141 \\
P=0.033\end{array}$ & $\begin{array}{c}\mathbf{0 . 5 6} \pm 0.130 \\
P<0.001 \\
12.7\end{array}$ \\
\hline Pollen volume & $\begin{array}{c}0.18 \pm 0.104 \\
P=0.085 \\
3.8\end{array}$ & $\begin{array}{c}-0.14 \pm 0.422 \\
P=0.75\end{array}$ & $\begin{array}{c}0.37 \pm 0.216 \\
P=0.11\end{array}$ & $\begin{array}{c}0.72 \pm 0.352 \\
P=0.057\end{array}$ & $\begin{array}{c}0.30 \pm 0.200 \\
P=0.14 \\
32\end{array}$ \\
\hline Corolla width & $\begin{array}{c}0.41 \pm 0.076 \\
P<0.001\end{array}$ & $\begin{array}{l}0.47 \pm 0.126 \\
P=0.0015\end{array}$ & $\begin{array}{c}\mathbf{0 . 5 7} \pm 0.118 \\
P<0.001\end{array}$ & $\begin{array}{c}\mathbf{0 . 5 4} \pm 0.101 \\
P<0.001\end{array}$ & $\begin{array}{c}0.54 \pm 0.082 \\
P<0.001\end{array}$ \\
\hline $\begin{array}{l}C V_{\mathrm{A}}(\%) \\
\text { Number of families }\end{array}$ & $\begin{array}{c}12.8 \\
34\end{array}$ & 19 & 19 & 19 & $\begin{array}{c}10.9 \\
53\end{array}$ \\
\hline
\end{tabular}

The values presented are the slopes of the regressions $\pm S E$ (the $S E$ of the slopes given in PROC REG in SAS, 1988).

Heritabilities in boldface are significantly greater than zero $(P<0.05)$.

To calculate $C V_{\mathrm{A}}\left(\right.$ Houle, 1992) for the $\mathrm{F}_{2}, h^{2}$ measurements for all $\mathrm{F}_{2}$ combined (all three growth environments) were used.

Table 4 Genetic correlations and SE using covariances calculated from mid-parent, mean offspring regressions

\begin{tabular}{lcccr}
\hline & Parents $\rightarrow F_{1}$ & & $F_{1} \rightarrow F_{2}$ & \\
\cline { 5 - 5 } & & Field 1 & Field 2 & GH \\
\hline $\begin{array}{c}\text { Pollen number and } \\
\text { pollen volume }\end{array}$ & $-0.26 \pm 0.266$ & $-0.24 \pm 0.612$ & $-0.19 \pm 0.282$ & $-0.17 \pm 0.314$ \\
$\begin{array}{c}\text { Pollen volume and } \\
\text { corolla width }\end{array}$ & $-0.07 \pm 0.230$ & $-0.16 \pm 0.575$ & $-0.25 \pm 0.225$ & $0.37 \pm 0.207$ \\
$\begin{array}{c}\text { Pollen number and } \\
\text { corolla width }\end{array}$ & $0.74^{* *} \pm 0.074$ & $0.61^{* *} \pm 0.113$ & $0.71^{* *} \pm 0.085$ & $0.58^{* *} \pm 0.147$ \\
\hline
\end{tabular}

Correlations are labelled as significant $\left.{ }^{* *}\right)$ if the correlation \pm 2 SE does not overlap with zero.

each environment. In contrast, Mazer \& Schick (1991a) working on wild radish also, found evidence of $\mathrm{G} \times \mathrm{E}$ for pollen production, pollen volume and flower size across three density treatments in the field. They also found variation in heritability estimates of pollen volume across these densities (Mazer \& Schick, 1991b). There are at least three explanations for the different sensitivities for heritability estimates in the two studies. (i) The density treatments of Mazer \& Schick may have greater effects on individuals of wild radish in general than the field and greenhouse treatments used in the present study. (ii) Populations and population samples may differ in the robustness of heritability estimates. Mazer \& Schick used seeds from a coastal $R$. sativus population, whereas we used seeds from inland populations. (iii) Differences between these two studies could also be explained by the different methods of quantifying $\mathrm{G} \times \mathrm{E}$ : Mazer \& Schick looked for differences in heritability across treatments as measures of $\mathrm{G} \times \mathrm{E}$; we used the family-by-site interaction term in ANOVA.
Given consistent heritabilities across environments for these traits, it is not obvious what maintains their observed phenotypic and genetic variation. We have eliminated strong $\mathrm{G} \times \mathrm{E}$ as a possibility to explain genetic variation in wild radish (Via \& Lande, 1987; Gillespie \& Turelli, 1989) but selection may be temporally or spatially variable (Kalisz, 1986; Schmitt \& Antonovics, 1986). Different communities of pollinators visit populations of radish of different sizes (Stanton et al., 1991): honey-bees are the dominant pollinators of large populations of radish, while solitary bees predominate in small populations (R. Neumeier and J. Conner observed similar differences in pollinator communities with respect to population size of Brassica nigra; personal observation). Since these insects have different visitation patterns and different effects on male reproductive success (Stanton et al., 1991), it is likely that selection on flower size and pollen production varies with population size. Therefore, selection may not be stabilizing across populations of radish, e.g. small flowers may be favoured in 
Fig. 3 Expected norms of reaction of two genotypes in two environments in the presence and absence of $\mathrm{G} \times \mathrm{E}$ and under conditions of consistency or nonconsistency of heritability across environments (some measure of phenotype is the $y$-axis). In this example, heritabilities are consistent across environments if the absolute difference between the phenotypes is approximately equal in the two environments. (a) The phenotype of each genotype is strongly influenced by the environment and the two genotypes respond differently to the two environments; however, with consistent heritability across the environments, predictions about future phenotypes can be made if the direction of selection is known in each environment. (b) With information on the relationship between the phenotypes and fitness, the direction of change in all environments is predictable and the same. (c) The direction and rate of change is unpredictable across environments; environmental variation is present and an offspring phenotype will depend on which environment it is in. As heritability is not consistent across environments, predictions about future phenotypes are difficult to make. (d) This is theoretically impossible: to have different phenotypic ratios in the two environments in the absence of $\mathrm{G} \times \mathrm{E}$.

one population and large flowers favoured in another. With extensive pollen and seed dispersal among populations, all populations would maintain genetic variation in floral traits (Stearns \& Sage, 1980; Mitchell-Olds \& Rutledge, 1986; Barton \& Turelli, 1989). Secondly, phenotypic (and genetic) variation can be maintained by positive assortative mating (Bulmer, 1980). Because honey-bees visit large flowers first and only later shift to smaller flowers (Young \& Stanton, 1991), they may be enforcing a positive assortative mating scheme on $R$. sativus. Thirdly, mutationselection balance in large populations can maintain large degrees of genetic variation (Lande, 1975; Charlesworth, 1987), although for genetic variation to be as large as that measured here, most of the genes undergoing mutation must affect most characters (Barton \& Turelli, 1989). Finally, if there is no selection on these traits (flat fitness profiles; Stearns, 1992), genetic variation can be maintained.

There are several lines of evidence supporting the existence of selection on these floral traits. Pollen pro-

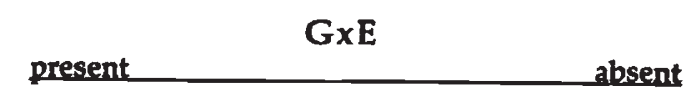

(a)

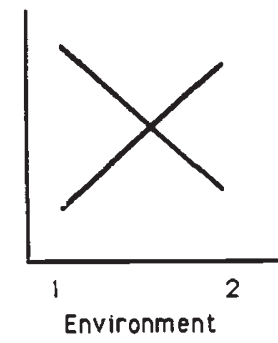

(c)

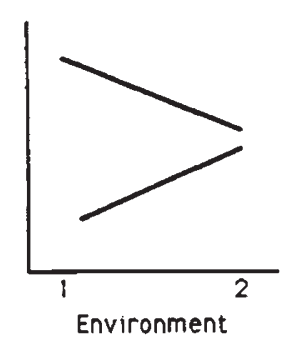

(b)

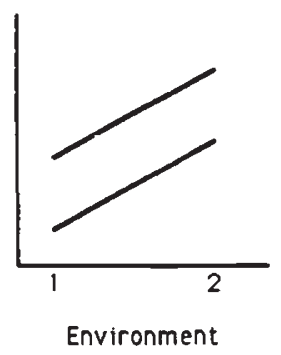

(d) duction has a positive influence on the quantity of pollen exported (Young \& Stanton, 1990; Stanton et al., 1992) and on the number of seeds sired in small artificial populations (Stanton et al., 1991). Selection on petal size is likely to be more complex. Although flower size is a positive predictor of the number of visits a flower receives, it is unrelated to the number of seeds sired in artificial arrays (Stanton et al., 1991) or the number of seeds produced by that flower (Stanton \& Preston, 1988). Larger flowers do have greater absolute pollen removal and proportion of pollen removed (Young \& Stanton, 1990) but apparently this does not translate into greater male reproductive success. Under natural conditions, large flowers may be favoured because they are visited first by pollinators: their stigmas will be dusted with fresh pollen and their pollen will be the first to land on the stigmas of other flowers. Ovule availability declines as the day progresses, suggesting that flowers that disperse their pollen early are likely to sire more seeds than those visited later in the day (Stanton et al., 1992; Ashman et 
al., 1993). Complicating the story is a negative phenotypic relationship between flower size and flower number (Stanton et al., 1991). The net fitness effects of varying flower size will depend not only on the flowerby-flower effects on reproductive components but also on the costs with respect to whole plant growth and reproduction. Evidence suggests that these traits are of sufficient ecological importance to warrant further genetical investigations in radish and in other species where flower size is heritable (Soltis, 1986; Mazer \& Schick, 1991b; Conner \& Via, 1993). However, it appears that selection on each trait is weak. With pollinator assemblages varying with radish population sizes, it is likely that the direction of selection also varies among populations (at least for corolla size), either with temporal or spatial changes in population size.

The effect of pollen size on pollen performance (pollen germination, pollen tube growth rate and fertilization ability) is relatively unexplored (but see Cruzan, 1990). Pollen volume may influence the probability of seed abortion in Erythronium (Cruzan, 1990) through the contributions of pollen tube cytoplasm to the endosperm (Russell, 1980); large pollen contribute more than small pollen. However, the importance of pollen size variation in wild radish is not well understood. It appears that pollen size, or some trait correlated with it, affects attractiveness to honey-bees in this species (Stanton et al., 1991). Plants with large pollen may be expected to have greater male fitness through increases in pollinator visits and pollen removal (if honcy-bees are effective pollinators and deposit pollen on receptive stigmas). However, because we found no significant degree of heritability of pollen size in this study, it is unlikely that this trait will respond to these selection pressures.

The coefficient of variation of additive genetic variance (Houle, 1992) varies for the three traits measured: the 'evolvabilities' of pollen production and corolla size are much greater (11-13 per cent) than that of pollen size (3-4 per cent). Evolvability is a measure of the amount of variation available on which selection can act, suggesting that pollen production and flower size will respond more rapidly to selection and in greater magnitude than will pollen size. Because we are suggesting that pollen production and flower size are likely to be under stronger selection pressures than pollen size, one might predict that genetic variation for those traits would be low. But the positive genetic correlation between pollen production and flower size may act to maintain substantial amounts of variation in the population. This genetic correlation is also likely to constrain the responses of each to selection. For instance, selection for increases in flower size will always by accompanicd by increases in pollen production. But, because there is a trade-off between flower size and flower number per plant (Stanton et al., 1991), there may be a negative association between male and female reproductive success. Large flowers experience greater pollen removal (which may lead to greater male success) but do not have greater female reproductive success than smaller flowers. Seed production may be increased by producing more and smaller flowers at the cost of reproductive success through male function. Optimal allocation to flower number and flower size may be different for male and female function and therefore appear to be a compromise between the two.

Although selection on floral traits may be patchy, both temporally and spatially, the genetic components of corolla size, pollen production and pollen size are relatively stable, at least over three sites and 2 years. Therefore, for wild radish, the information needed to make long-term predictions about changes in floral phenotype is the direction and strength of selection on each trait in different environments through time and the distribution of those environments.

\section{Acknowledgements}

We are grateful to all who helped at various stages in this project. R. Nakamura assisted with pollinations and B. Riska and D. Stratton assisted with statistics. We thank D. Stratton, A. Snow, S. Mazer, M. Turelli, 'T. Mitchell-Olds, J. Antonovics, J. Conner and D. Houle for helpful discussions. This research was supported by NSF grants BSR-8516333 and BSR-8914583 to M. Stanton, BSR-85-05982 to N. Ellstrand and BSR9106864 to $\mathrm{H}$. Young.

\section{References}

Anronovics, J. 1976. The limits to selection. Ann. Mo. Bot. Gard., 63, 224-247.

ASHMAN, T.-L., Galloway, 1. F. AND STANTON, M. 1. 1993. Apparent vs. cffective mating in an experimental population of Raphanus sativus. Oecologia, 96, 102-107.

BARTON, N. H. AND TURFILI., M. 1989. Evolutionary quantitative genctics: how little do we know? Ann. Rev. Genet., 23, 337-370.

BOAG, P. T. 1983. The heritability of external morphology in Darwin's ground finches (Geospiza) on Isla Daphne Major, Galapagos. Evolution, 37, 877-894.

BUl.MER, M. G. 1980. The Mathematical Theory of Quantitative Genetics. Clarendon Press, Oxford.

CHARLESWORTH, B. 1987. The heritability of fitness. In: Bradbury, J. W. and Anderson, M. B. (eds) Sexual Selection: Testing the Alternatives, pp. 21-40. John Wilcy, New York. 
CONNER, J. AND VIA, S. 1993. Patterns of phenotypic and genetic correlations among morphological and life-history traits in wild radish, Raphanus raphanistrum. Evolution, 47, 704-711.

COYNE, J. A. AND BeECHAM. E. 1987. Heritability of two morphological characters within and among populations of Drosophila melanogaster. Genetics, 117, 727-737.

CRUZAN, M. B. 1990. Variation in pollen size, fertilization ability and postfertilization siring ability in Erythronium grandiflorum. Evolution, 44, 843-856.

ELLSTRAND, N. C. 1984. Multiple paternity within the fruits of the wild radish, Raphanus sativus. Am. Nat., 123, 819-828.

FALCONER, D. S. 1989. Introduction to Quantitative Genetics, 3rd edn. Longman, London, UK.

GIESEL, J. T., MURPhY, P. A. AND MANLOVE, M. N. 1982. The influence of temperature on genetic interrelationships of life history in a population of Drosophila melanogaster. what tangled data sets we weave. Am. Nat., 119, 464-479.

GILLESPIE, J. H. AND TURELLI, M. 1989. Genotype-environment interactions and the maintenance of polygenic variation. Genetics, 121, 129-138.

GIMELFARB, A. 1985. Is offspring-midparent regression affected by assortative mating of parents? Genet. Res., 47, 71-75.

GUSTAFSSON, L. 1986. Lifetime reproductive success and heritability: empirical support for Fisher's fundamental theorem. Am. Nat., 128, 761-764.

HOULE, D. 1992. Comparing evolvability and variability of quantitative traits. Genetics, 130, 195-204.

JORDAN, N. 1991. Multivariate analysis of selection in experimental populations derived from hybridization of two ecotypes of the annual plant Diodia teres W. (Rubiaceae). Evolution, 45, 1760-1772.

KALISZ, s. 1986. Variable selection on the timing of germination in Collinsia verna (Scrophulariaceae). Evolution, 40, 479-491.

KUMAR, D. AND SARKAR, K. R. 1980. Correlation between pollen diameter and rate of pollen tube growth in maize (Zea mays L.) Ind. J. Exp. Biol., 18, 1242-1244.

LANDE, R. 1975. The maintenance of genetic variability by mutation in a polygenic character with linked loci. Genet. Res., 26, 221-235.

LANDE, R. AND ARNOLD, s. J. 1983. The measurement of selection on correlated characters. Evolution, 37, 1210-1226.

LEAMY, L. 1988. Genetic and maternal influences on brain and body size in randombred house mice. Evolution, 42, 42-53.

MARSHALL, D. L. AND ELLSTRAND, N. C. 1986. Sexual selection in Raphanus sativus: experimental data on non-random fertilization, maternal choice and consequences of multiple paternity. Am. Nat., 127, 446-461.

MAZER, S. J. AND SCHICK, C. T. 1991a. Constancy of population parameters for life history and floral traits in Raphanus sativus L. I. Norms of reaction and the nature of genotype by environmental interactions. Heredity, 67, 143-156.

MAZER, S. J. AND SCHICK, C. T. 1991b. Constancy of population parameters for life-history and floral traits in Raphanus sativus L. II. Effects of planting density on phenotype and heritability estimates. Evolution, 45, 1888-1907.
MITCHELL-OLDS, T. 1986. Quantitative genetics of survival and growth in Impatiens capensis. Evolution, 40, 107-116.

MITCHELL-OLDS, T. AND RUTLEDGE, J. J. 1986. Quantitative genetics in natural populations: a review of the theory. Am. Nat., 127, 379-402.

MOUSSEAU, T. A. AND ROFF, D. A. 1987. Natural selection and the heritability of fitness components. Heredity, 59, 181-197.

PANETSOS, C. P. AND BAKER, H. G. 1967. The origin of variation in 'wild' Raphanus sativus (Cruciferae) in California. Geneti$c a, 38,243-274$.

POTVIN, C., LECHOWICZ, M. J., BELL, G. AND SCHOEN, D. 1990. Spatial, temporal and species-specific patterns of heterogeneity in growth chamber experiments. Can. J. Bot., 68, 499-504.

PRICE, T. AND SCHLUTER, D. 1991. On the low heritability of lifehistory traits. Evolution, 45, 853-861.

RISKA, B., PROUT, T. AND TURELLI, M. 1989. Laboratory estimates of heritabilities and genetic correlations in nature. Genetics, 123, 865-871.

ROFF, D. A. AND MOUSSEAU, T. A. 1987. Quantitative genetics and fitness: lessons from Drosophila. Heredity, 58, 103-118.

RUSSELL, S. D. 1980. Participation of male cytoplasm during gamete fusion in an angiosperm, Plumbago zeylandica. Science, 210, 200-201.

SAS INSTITUTE INC. 1988. SAS/STAT User's Guide, Release 6.03 Edition. SAS Institute Inc., Cary, NC.

SCHMITT, J. AND ANTONOVICS, J. 1986. Experimental studies of the evolutionary significance of sexual reproduction. III. Maternal and paternal effects during seedling establishment. Evolution, 40, 817-829.

SOLTIS, P. S. 1986. Estimates of heritability and correlations of morphometric traits in Clarkia (Onagraceae). Theor. Appl. Genet., 73, 88-93.

STANTON, M. L. 1987. The reproductive biology of petal color variants in wild populations of Raphanus sativus L.: I. Pollinator response to color morphs. Am. J. Bot., 74, 178-187.

STANTON, M. L., ASHMAN, T.-L., GALlOWAY, L. F. AND YOUNG, H. J. 1992. Estimating male fitness of plants in natural populations. In: Wyatt, R. (ed.) Ecology and Evolution of Plant Reproduction, pp. 62-90. Chapman \& Hall, New York.

STANTON, M. L. AND GALlowAY, L. F. 1990. Natural selection and allocation to reproduction in flowering plants. Lectures on Mathematics in the Life Sciences, 22, 1-50.

STANTON, M. L. AND PRESTON, R. E. 1986. Pollen allocation in wild radish: variation in pollen grain size and number. In: Mulcahy, D., Mulcahy, G. B. and Ottaviano, E. (eds) Biotechnology and Ecology of Pollen, pp. 461-466. SpringerVerlag, New York.

STANTON, M. L. AND PRESTON, R. E. 1988. Ecological consequences and phenotypic correlates of petal size variation in wild radish, Raphanus sativus (Brassicaceae). Am. J. Bot., 75, 528-539.

STANTON, M. L., YOUNG, H. J., ELlSTRAND, N. C. AND CLEGG, J. M. 1991. Consequences of floral variation for male and female reproduction in experimental populations of wild radish, Raphanus sativus. Evolution, 45, 268-280.

STEARNS, s. C. 1980. A new view of life-history evolution. Oikos, 35, 266-281. 
STEARnS, s. c. 1992. The Evolution of Life Histories. Oxford University Press, New York.

STEARNS, S. C. AND SAGE, R. D. 1980. Maladaptation in a marginal population of the mosquito fish, Gambusia affinis. Evolution, 34, 65-75.

STRA'TTON, D. A. 1992a. Life-cycle components of selection in Erigeron annuus: I. Phenotypic selection. Evolution, 46, 92-106.

STRATTON, D. A. 1992b. Life-cycle components of selection in
Erigeron annuus: II. Genetic variation. Evolution, 46, 107-120.

VIA, S. AND LANDE, R. 1987. Evolution of genetic variability in a spatially heterogeneous environment: effects of genotype-environment interaction. Genet. Res., 49, 147-156.

YOUNG, H. J. AND STANTON, M. L. 1990. Influences of floral variation on pollen removal and seed production in wild radish. Ecology, 71, 536-547. 